\title{
Double cusp encounter by Cluster: double cusp or motion of the cusp?
}

\author{
C. P. Escoubet ${ }^{1}$, J. Berchem ${ }^{2}$, K. J. Trattner ${ }^{3}$, F. Pitout ${ }^{4,5}$, R. Richard ${ }^{2}$, M. G. G. T. Taylor ${ }^{1}$, J. Soucek ${ }^{6}$, B. Grison ${ }^{6}$, \\ H. Laakso ${ }^{1}$, A. Masson ${ }^{1}$, M. Dunlop ${ }^{7}$, I. Dandouras ${ }^{4,5}$, H. Reme ${ }^{4,5}$, A. Fazakerley ${ }^{8}$, and P. Daly ${ }^{9}$ \\ ${ }^{1}$ European Space Agency/European Space Research and Technology Centre (ESA/ESTEC), Noordwijk, the Netherlands \\ ${ }^{2}$ University of California Los Angeles/ Institute of Geophysics and Planetary Physics (UCLA/IGPP), Los Angeles, USA \\ ${ }^{3}$ Lockheed Martin ATC, Palo Alto, USA \\ ${ }^{4}$ University of Toulouse, UPS-OMP, Institut de Recherche en Astrophysique et Planétologie (IRAP), Toulouse, France \\ ${ }^{5}$ Centre national de la recherche scientifique/Institut de Recherche en Astrophysique et Planétologie, CNRS, BP 44346, \\ 31028, Toulouse cedex 4, France \\ ${ }^{6}$ Institute of Atmospheric Physics, Prague, Czech Republic \\ ${ }^{7}$ Rutherford Appleton Laboratory Space/Science and Technology Facilities Council, Harwell Oxford, UK \\ ${ }^{8}$ Mullard Space Science Laboratory (MSSL), Holmbury St. Mary, UK \\ ${ }^{9}$ Max Planck Institute for Solar System Research, Lindau, Germany \\ Correspondence to: C. P. Escoubet (philippe.escoubet@esa.int)
}

Received: 30 November 2012 - Revised: 25 March 2013 - Accepted: 25 March 2013 - Published: 19 April 2013

\begin{abstract}
Modelling plasma entry in the polar cusp has been successful in reproducing ion dispersions observed in the cusp at low and mid-altitudes. The use of a realistic convection pattern, when the IMF- $B_{\mathrm{y}}$ is large and stable, allowed Wing et al. (2001) to predict double cusp signatures that were subsequently observed by the DMSP spacecraft. In this paper we present a cusp crossing where two cusp populations are observed, separated by a gap around $1^{\circ}$ Invariant Latitude (ILAT) wide. Cluster 1 (C1) and Cluster 2 (C2) observed these two cusp populations with a time delay of $3 \mathrm{~min}$, and about 15 and 42 min later Cluster 4 (C4) and Cluster 3 (C3) observed, respectively, a single cusp population. A peculiarity of this event is the fact that the second cusp population seen on $\mathrm{C} 1$ and $\mathrm{C} 2$ was observed at the same time as the first cusp population on $\mathrm{C} 4$. This would tend to suggest that the two cusp populations had spatial features similar to the double cusp. Due to the nested crossing of $\mathrm{C} 1$ and $\mathrm{C} 2$ through the gap between the two cusp populations, $\mathrm{C} 2$ being first to leave the cusp and last to re-enter it, these observations are difficult to be explained by two distinct cusps with a gap in between. However, since we observe the cusp in a narrow area of local time post-noon, a second cusp may have been present in the pre-noon sector but could not be observed. On the other hand, these observations are in agreement with a
\end{abstract}

motion of the cusp first dawnward and then back duskward due to the effect of the IMF- $B_{\mathrm{y}}$ component.

Keywords. Magnetospheric physics (Magnetopause, cusp, and boundary layers)

\section{Introduction}

The polar cusp was first observed from space by Heikkila and Winningham (1971) using the low-altitude spacecraft ISIS 1 and a few months later by Frank (1971) using the high-altitude satellite IMP-5. Since the electron and protons had similar energy and flux as in the magnetosheath, these authors proposed that the solar wind plasma entered directly into the cusp through the high-altitude neutral point/line at the magnetopause.

Only a few years later, based on the mechanism of energy dispersion first proposed by Rosenbauer et al. (1975), Shelley et al. (1976) correlated the velocity of the precipitating ions with latitude and estimated the dawn-dusk electric field around $30-60 \mathrm{mV} \mathrm{m}^{-1}$. Ion dispersions were starting to be the key observations in the analysis of the entry mechanisms of particles in the polar cusp. Reiff et al. (1977) analysed in more detail the ion dispersions observed by AE-C 
satellite and showed that most dispersions were in agreement with the reconnection model, although a few were also consistent with the cross-field diffusion mechanism.

Burch et al. (1980) showed a case study under northward IMF- $B_{\mathrm{Z}}$ where the dispersion was forming a "V" with first a decrease in the energy of the ions and then an increase associated with stronger fluxes. Reiff et al. (1980) analysed 60 passes of AE-D crossing in the polar cusp associated with measurements of the interplanetary magnetic field. They showed that the poleward dispersions, energy decreasing with increasing latitude, were occurring under IMF$B_{\mathrm{Z}}$ southward and the V-shaped dispersions under IMF- $B_{\mathrm{Z}}$ northward. At that time, to explain the V-shaped dispersion, the authors could not distinguish between (1) a cross-field diffusion mechanism, (2) a mixture of diffusion and reconnection in the lobes or (3) a reconnection in the lobes and on the dayside of the magnetosphere occurring simultaneously. This later entry mechanism was more hypothetical since it did not fit with the trapped particles location.

It took many more years to demonstrate, using ground based observations, modelling and multi-point observations, that the cusp could be populated by different sources simultaneously. Sandholt et al. (1998) showed that two types of auroras (one for IMF north and one for the south) could coexist when the IMF is rotating slowly from south to north with a dominant $B_{\mathrm{y}}$ component. The term "double cusp" was first proposed by Wing et al. (2001) when they simulated ion precipitation and introduced a more realistic electric field model with a north-south component. Their simulation showed that the two reconnection sites (low and high latitude) under strong and stable IMF- $B_{\mathrm{y}}$ were producing two plasma injections into the cusp that could be distinguished by a gap of particle precipitation in between or by the different shape of the ion dispersion. Pitout et al. (2002) used EISCAT and DMSP observations to demonstrate that reconnection at low and high latitude could take place simultaneously, producing a double cusp in the ionosphere. Trattner et al. (2005) observed a double cusp with two Cluster spacecraft and, using IMAGE and ground based data, found that the two ion dispersions had a distinct origin, one in the Southern Hemisphere on the duskside and one in the Northern Hemisphere on the dawnside, produced by anti-parallel reconnection. About $75 \%$ of the DMSP crossings (Wing et al., 2001) under strong positive or negative IMF- $B_{\mathrm{y}}$ were showing double cusps or cusps with extended latitudinal width. A few years later, Escoubet et al. (2008a) showed that the cusp was changing from a poleward to a $\mathrm{V}$-shaped dispersion in a few minutes after the turning of the IMF from southward to northward-westward. The poleward side of the $\mathrm{V}$ shape was consistent with reconnection in the lobes, while the equatorward side was consistent with closure of the reconnected field lines in the Southern Hemisphere. In a case study, Escoubet et al. (2008b) showed that the cusp could be populated by two sources - one at low latitude and one at high latitude under strong IMF- $B_{\mathrm{y}}$. Subsequently, Pitout et al. (2009) analysed four years of Cluster observations in the mid-altitude cusp and showed that the cusp with a "discontinuous" dispersion, to which the V-shaped ones belong, occurred in the majority when the IMF had a clear rotation during the cusp crossing. Using multi-point observations with Cluster and Double Star spacecraft at the magnetopause, Berchem et al. (2008) and Dunlop et al. (2009) showed that indeed anti-parallel reconnection could occur at both high latitude and component reconnection near the sub-solar point quasi-simultaneously.

Generally, at low altitude, only single spacecraft crossed the cusp at any given time, except during some fortuitous conjunction (Escoubet et al., 1997; Newell et al., 2010). There are therefore no low-altitude multi-point observations that could help us to understand the evolution of a double cusp. We could, however, use the four-point Cluster observations in the mid-altitude cusp (4-5 $R_{\mathrm{E}}$ geocentric distance) to investigate the evolution of double cusp. This study investigates two cusp populations observed consecutively by the Cluster spacecraft on 20 August 2002 and uses multispacecraft capabilities, with the four spacecraft crossing the cusp separated by a few minutes to a few tens of minutes, to observe their evolution in time. A very puzzling feature of that event is that the first two Cluster spacecraft observed a double cusp population and the last two spacecraft a single one. We investigate if changes occurring in the interplanetary medium could explain these observations. In Sect. 2 we present the interplanetary conditions during the cusp crossings, and the Cluster spacecraft positions are presented in Sect. 3. In Sect. 4 we present the Cluster observations and, finally, these observations are discussed in Sect. 5.

\section{Solar wind conditions}

Figure 1 shows the solar wind conditions on 20 August 2002 measured by ACE spacecraft. ACE measurements (propagated to the nose of the bow shock) were provided by Omniweb at NSSDC. A $10 \mathrm{~min}$ delay was added to these data to take into account the propagation from the bow shock to the mid-altitude cusp. Figure 1 presents, from top to bottom, the three components of the IMF in GSM, the solar wind density, the solar wind speed and the solar wind dynamic pressure. Before 04:00 UT, $B_{\mathrm{x}}$ was fairly constant around $4 \mathrm{nT}$, and $B_{\mathrm{z}}$ and $B_{\mathrm{y}}$ were oscillating between $-6 \mathrm{nT}$ and $-2 \mathrm{nT}$, being dominant alternatively for a few tens of minutes. During the cusp-crossing intervals, marked by the two vertical lines, $B_{\mathrm{z}}$ and $B_{\mathrm{y}}$ were equal around $-4 \mathrm{nT}$ before 04:10 UT, then $B_{\mathrm{y}}$ became smaller than $B_{\mathrm{Z}}(-6 \mathrm{nT}$ vs. $-3 \mathrm{nT})$ for about $6 \mathrm{~min}$ and after 04:18 UT, $B_{\mathrm{z}}$ was larger than $B_{\mathrm{y}}(-7 \mathrm{nT}$ vs. $-3-0 \mathrm{nT}$ ) up to 05:00 UT. The solar wind density was oscillating between 2 and $4 \mathrm{~cm}^{-3}$. The solar wind speed was fairly high and constant around $480 \mathrm{~km} \mathrm{~s}^{-1}$. Finally, the solar wind dynamic pressure was fairly low, oscillating between 0.6 and $1.4 \mathrm{nPa}$. 


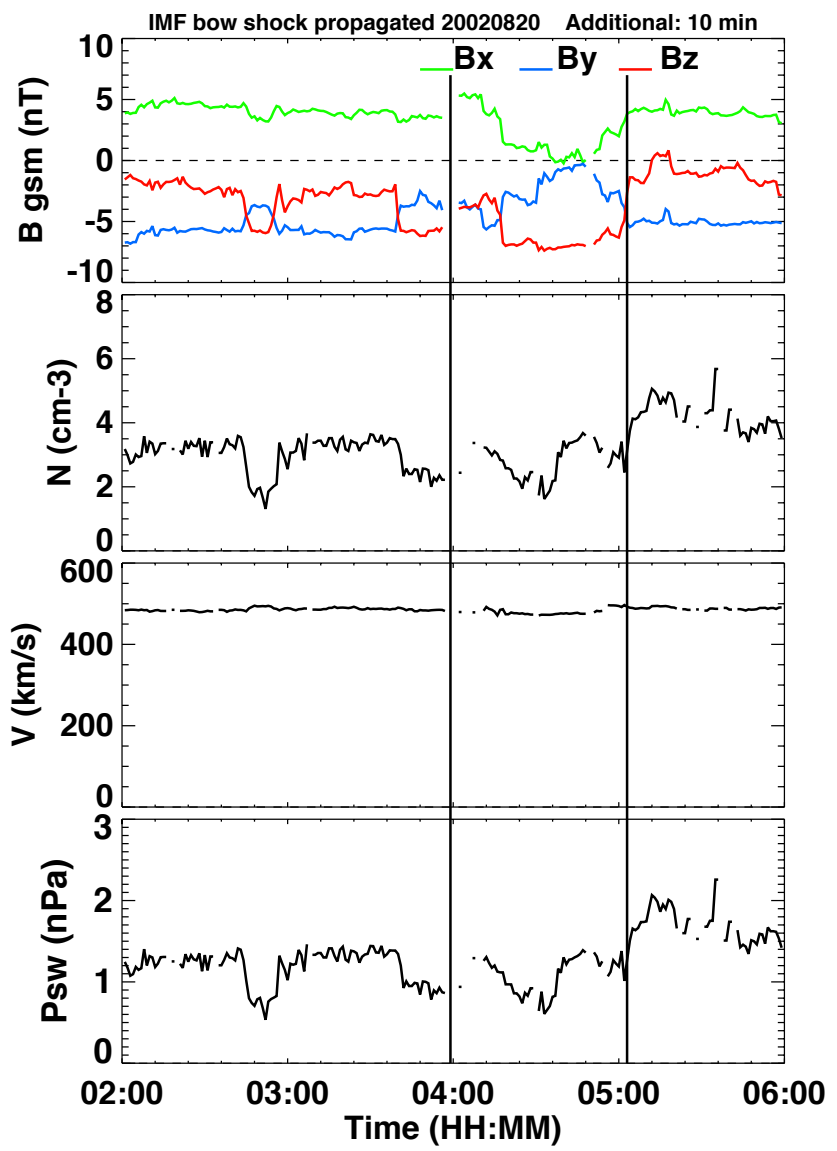

Fig. 1. Interplanetary magnetic field on 20 August 2002 propagated to the bow shock (omniweb), to which an additional 10 min has been added for the propagation from the bow shock to the mid-altitude cusp. Top panel shows the three components of the IMF in GSM coordinate system. The 2 nd panel from the top shows the solar wind density, and the 3 rd panel from the top the solar wind speed. Bottom panel shows the solar wind dynamic pressure. Vertical lines mark the interval when the cusp was crossed by the Cluster spacecraft.

\section{The Cluster orbit and instrumentation}

The Cluster mission consists of four spacecraft each carrying 11 identical instruments that allow for the first time distinguishing between spatial and temporal changes in the Earth's environment (Escoubet et al., 2001). The spacecraft were launched in 2000 into a polar orbit of $4 R_{\mathrm{E}} \times 19.6 R_{\mathrm{E}}$, allowing them to sample the mid-altitude cusp and the nearEarth tail when the apogee was on the nightside, and the auroral zone, external cusp/magnetopause and bow shock when the apogee was on the dayside, 6 months later. In summer 2002 the spacecraft were placed into a perfect tetrahedron of $4000 \mathrm{~km}$ size in the tail, and due to orbital mechanics, they followed each other in a "string of pearls" in the midaltitude cusp with a time difference from a few minutes to a few tens of minutes.
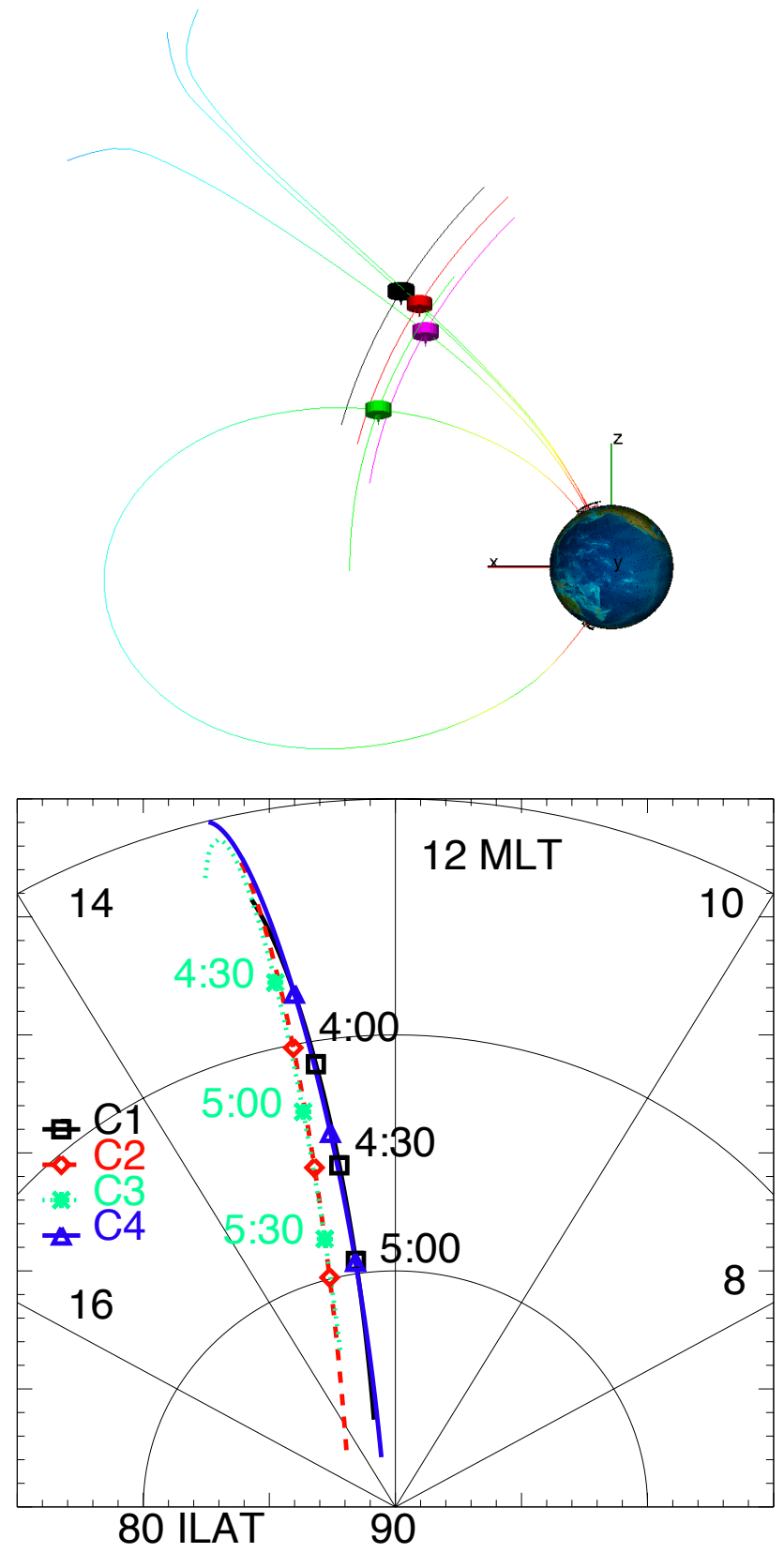

Fig. 2. Top: Cluster orbit in $X-Y_{\mathrm{GSM}}$ plane at 04:30 UT on $20 \mathrm{Au}-$ gust 2002. Bottom: projection of orbit track in ILAT-MLT diagram. The colours of the spacecraft are the usual Cluster colours $(\mathrm{C} 1$, black; C2, red; C3, green; C4, blue). The times on the right of the orbit tracks are associated with the positions of the three spacecraft $\mathrm{C} 1, \mathrm{C} 2$ and $\mathrm{C} 4$ and the times on the left to $\mathrm{C} 3$. The time delays of the cusp entry, around $71^{\circ} \mathrm{ILAT}$, are $\mathrm{d} t 12=5 \mathrm{~min}, \mathrm{~d} t 14=15 \mathrm{~min}$ and $\mathrm{d} t 13=50 \mathrm{~min}$.

Figure 2 shows the Cluster positions in the mid-altitude cusp (only a portion of the orbit is shown) on $20 \mathrm{Au}$ gust 2002. The top panel displays the spacecraft positions in GSM and the field lines (Tsyganenko and Stern, 1996) that passed by each spacecraft position at 04:30 UT. The first 


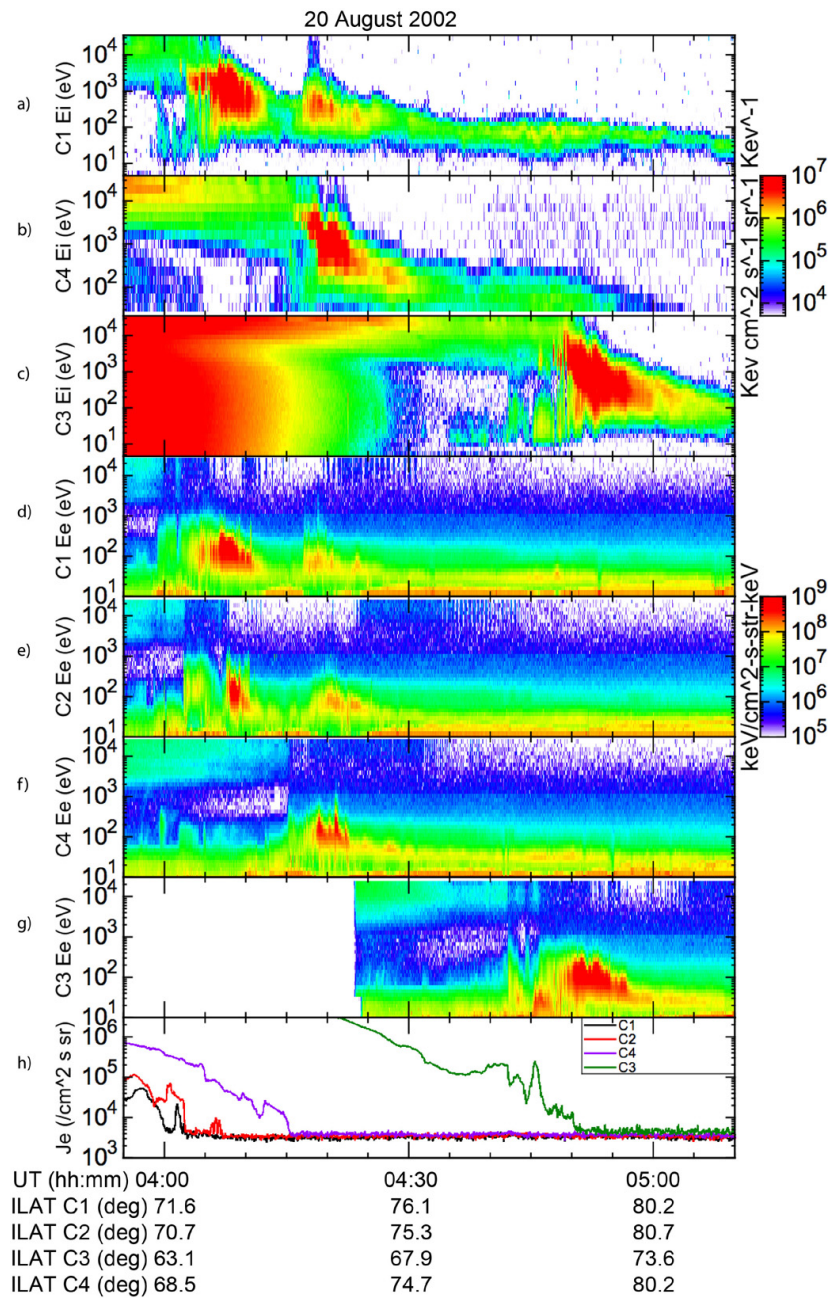

Fig. 3. Omnidirectional ion (CIS) and electron (PEACE) spectrograms on (a), (d) C1; (e) C2; (b), (d) C4; and (c), (g) C3 on $20 \mathrm{Au}-$ gust 2002. The last panel (h) shows the integrated flux of electrons (RAPID) between 50 and $400 \mathrm{keV}$ from the four spacecraft.

three Cluster spacecraft $\mathrm{C} 1, \mathrm{C} 2$ and $\mathrm{C} 4$ were close to each other in the polar cusp, while C3 was lagging behind on closed field lines. C1 was leading, followed by $\mathrm{C} 2(5 \mathrm{~min}$ later), C4 (15 min later) and finally C3 (50 min later). The bottom panel shows the track of each spacecraft projected in an ILAT-MLT diagram. Although very close in local time, the spacecraft were travelling in pairs separated by 0.1 to $0.4 \mathrm{~h}$ Magnetic Local Time (MLT). At 04:20 UT, C1 and C2 were separated by $0.2^{\circ}$ Invariant Latitude (ILAT), $\mathrm{C} 1$ and $\mathrm{C} 4$ by $2^{\circ}$ ILAT, and $\mathrm{C} 1$ and $\mathrm{C} 3$ by $8^{\circ}$ ILAT.

This study uses data from the ion spectrometer CIS (Rème et al., 2001), the electron detector PEACE (Johnstone et al., 1997), and the energetic electrons instrument RAPID (Wilken et al., 2001).

\section{Cluster observations}

Figure 3 displays ion and electron spectrograms as well as the energetic particle fluxes between 03:55 UT and 05:10 UT on 20 August 2002. The spacecraft were moving from the equator to the pole, and the invariant latitude of $\mathrm{C} 1$ was 71.6 ILAT at 04:00 UT and 80.2 $2^{\circ}$ ILAT at 05:00 UT. The top three panels (a, b and c) show $\mathrm{C} 1, \mathrm{C} 4$ and $\mathrm{C} 3$ ion omnidirectional spectrograms as the three spacecraft crossed successively the cusp. The following 4 panels ( $d, e, f$ and $g$ ) show the electron omnidirectional spectrograms from $\mathrm{C} 1, \mathrm{C} 2, \mathrm{C} 4$ and $\mathrm{C} 3$, also in time order, and finally the last panel (h) shows the energetic particle (electrons above $50 \mathrm{keV}$ ) fluxes measured by the four spacecraft. At the beginning of the event, before around 04:00 UT, all four spacecraft were on closed field lines, characterised by trapped energetic ions and electrons above a few $\mathrm{keV}$ (panels a to g) and high flux of energetic electrons above $50 \mathrm{keV}$ (panel h). C1 was the first spacecraft to enter the polar cusp at around 03:59:13 UT, characterised by high fluxes of ions from $100 \mathrm{eV}$ to a few $\mathrm{keV}$ (panel a) and high fluxes of electrons from a few tens of $\mathrm{eV}$ to a few hundred $\mathrm{eV}$ (panel d) of magnetosheath origin. The ion precipitation observed by $\mathrm{C} 1$ presents an energy dispersion with energy decreasing as the spacecraft moved poleward between 04:03 UT and 04:11 UT, typical for IMF- $B_{\mathrm{Z}}<0$. Then at 04:11 UT, the dispersion seen by $\mathrm{C} 1$ stopped abruptly for about $6 \mathrm{~min}$ and then restarted at 04:17 UT with the encounter of a second dispersion. The first cusp at 04:08 UT is characterised by high flux of ions and electrons and the second cusp at 04:19 UT by lower fluxes and slightly lower energy. After 04:24 UT a very low energy population of ions (below $100 \mathrm{eV}$ ) is observed up to 05:10 UT; these are oxygen ions outflowing from the cusp and filling up the plasma mantle. $\mathrm{C} 4$, the third spacecraft (the second with ion data), entered the cusp at 04:15 (panel b) and observed the poleward ion dispersion with energy decreasing with latitude up to around 04:30 UT. After that time it observed the plasma mantle. It is interesting to note that the single cusp observed by $\mathrm{C} 4$ is detected at the same time as the second cusp observed by C1. Finally, C3 entered the cusp around 04:42 UT and observed again a single cusp with a poleward ion dispersion (panel c).

There are no ion data on $\mathrm{C} 2$ (ion detector is off), but the electron data can be used to get more information since $\mathrm{C} 2$ was located in between $\mathrm{C} 1$ and $\mathrm{C} 4$. C2 entered the cusp at 04:02:24 UT (panel e) as can be seen with the increase of low-energy electrons (below $100 \mathrm{eV}$ ). $\mathrm{C} 2$ also observed the cusp disappearing around 04:10:30 UT (panel e), which is about $1 \mathrm{~min}$ before $\mathrm{C} 1$ (panel d). Then $\mathrm{C} 2$ observed a low flux electron precipitation, comparable to the mantle region observed after 04:30 UT, for about $7 \mathrm{~min}$. Note that this interval of low flux does not contain energetic electrons (red line on panel $\mathrm{h}$ ) and is therefore not due to the return of the spacecraft on closed field lines. $\mathrm{C} 2$ encountered the second cusp at 04:18 UT, about $1 \mathrm{~min}$ later than $\mathrm{C} 1$. After $10 \mathrm{~min}$ in this 
second cusp, C2 finally entered the plasma mantle around 04:27:45 UT. It is also clear on the electron spectrograms that this second cusp observed by both $\mathrm{C} 1$ and $\mathrm{C} 2$ shows lower fluxes than the first cusp. The electron density is also lower, as can be seen in the top panel of Fig. 5. C1 and C2 density is in the range $3-4 \mathrm{~cm}^{-3}$ in the second cusp around 04:20 UT, while it is above $10 \mathrm{~cm}^{-3}$ in the first cusp around 05:08 UT. The first and second cusp can also be compared simultaneously with $\mathrm{C} 4$ density reaching $13 \mathrm{~cm}^{-3}$ in the first cusp and $\mathrm{C} 1 / \mathrm{C} 2$ density in the range $3-4 \mathrm{~cm}^{-3}$ around the same time. Since the solar wind density around 04:08 UT was $3.4 \mathrm{~cm}^{-3}$ and down to $2.6 \mathrm{~cm}^{-3}$ around 04:19 UT, it could explain the decrease of density between the first cusp observed by $\mathrm{C} 1$ and $\mathrm{C} 2$, with a maximum around $17 \mathrm{~cm}^{-3}$, and the cusp observed by $\mathrm{C} 4$ around $13 \mathrm{~cm}^{-3}$.

The polar cusp, by definition, lies on open field lines, as can be seen on Fig. 3 with the decrease of flux of energetic electrons above $50 \mathrm{keV}$ (panel h). The sharp decrease occurred on the equatorward boundary of the cusp at the time when low energy electron and ions from the magnetosheath started to be observed in the cusp. At 04:02 UT and 04:06 UT, $\mathrm{C} 1$ (black line on panel h) and C2 (red line) observed, respectively, a burst of energetic electrons a few minutes after the drop-out at the entry of the cusp. This is most likely due to the motion of the cusp poleward (since the speed of the cusp at mid-altitude can be larger than the speed of the satellites) causing the spacecraft to move out of the cusp and back onto closed field lines for a few minutes.

\section{Double cusp or motion of the cusp}

We will investigate if the two cusps encountered by the first two spacecraft could be two separate cusps, as observed by Wing et al. (2001), or whether they are the same cusp encountered twice due to its motion, driven by external changes in solar wind conditions.

If two separate cusps existed simultaneously, we should be able to observe them at two different latitudes simultaneously. We can test this hypothesis since we have multiple spacecraft crossing the cusp. The fact that $\mathrm{C} 1$ and $\mathrm{C} 2 \mathrm{ob}-$ served the second cusp around 04:20 UT while C4 observed the first cusp at the same time, even though being located more than $2^{\circ}$ ILAT equatorward, would suggest that we have indeed two separate cusps. We cannot however exclude that these three spacecraft observe the same cusp at 04:20 UT since for IMF- $B_{\mathrm{Z}}=-3 \mathrm{nT}$, the cusp could be up to $4.5^{\circ} \mathrm{ILAT}$ wide (Pitout et al., 2006b), which is larger than the separation between $\mathrm{C} 1$ and $\mathrm{C} 4$. The second aspect that we can test in favour of a double cusp is whether we observe a spatial gap between the two cusps. Figure 4 is a sketch of the two spacecraft crossing two cusps separated by a gap of precipitation. We assume that no change occurs between the two spacecraft crossings separated by a few minutes and that the two cusps are similar, which may not be the case in reality (see

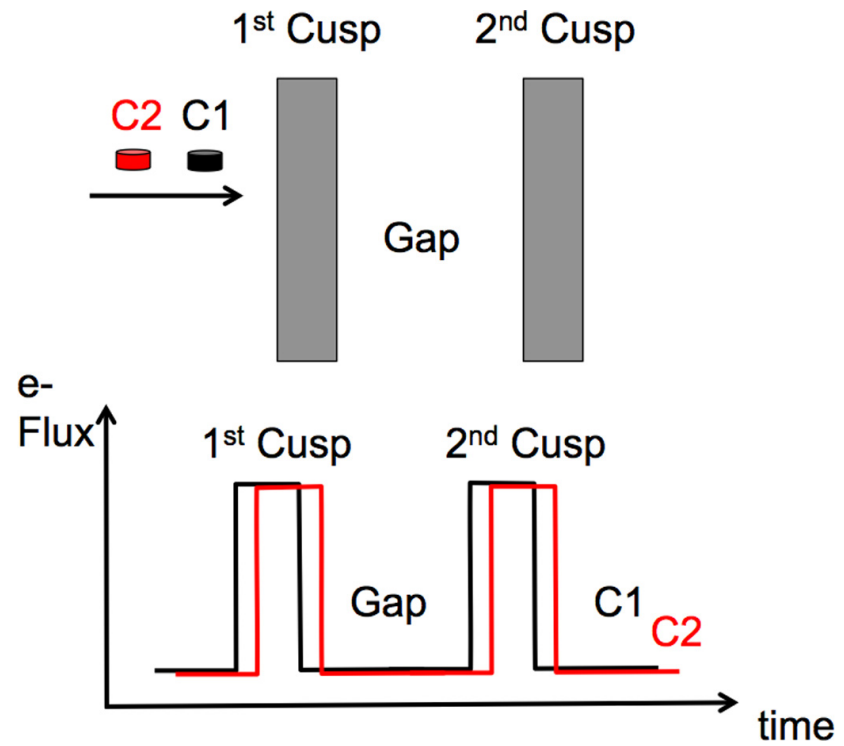

Fig. 4. Sketch of two separated cusps crossed by $\mathrm{C} 1$ and $\mathrm{C} 2$ in space (top) and the corresponding flux of electrons measured by $\mathrm{C} 1$ (black) and C2 (red) (bottom) as a function of time.

Wing et al., 2001). However, since we are only interested in comparing the order of the exit and re-entry of $\mathrm{C} 1$ and $\mathrm{C} 2$ in the cusp, this assumption should be valid. $\mathrm{C} 1$ would enter the gap first, characterised by the decrease of flux, followed by $\mathrm{C} 2$; later on, $\mathrm{C} 1$ would leave the gap first, followed $\mathrm{C} 2$. If we compare these fluxes with the observations on Fig. 5 (2nd panel from the top), we do not observe the same profiles. Although we observe the exit of the gap as expected with $\mathrm{C} 1$ (04:17 UT) leading C2 (04:18 UT), C2 entered the gap first at 04:10:13 UT and then $\mathrm{C} 1$ at 04:10:41 UT - the opposite of what we expected from the sketch. Therefore, this simple scenario with a gap in between two cusps is not observed in this event.

Could these observations be explained by the motion of the cusp? Since its discovery in early 1970s, the cusp has been known to change its position following changes in interplanetary conditions (Burch, 1972). The IMF $B_{\mathrm{Z}}$ would move the cusp in the north-south direction (e.g. Carbary and Meng, 1986; Escoubet and Bosqued, 1989; Woch and Lundin, 1992; Newell and Meng, 1994; Sandholt et al., 1994; Zhou et al., 2000; Wing et al., 2001; Pitout et al., 2006a, b), while the IMF- $B_{\mathrm{y}}$ would move the cusp in the east-west direction (e.g. Candidi et al., 1983; Crooker et al., 1987; Newell et al., 1989). The 3rd panel from the top of Fig. 5 shows the IMF changes during the cusp crossing of $\mathrm{C} 1$ and $\mathrm{C} 2$. During the 1 st cusp crossing, the IMF $B_{\mathrm{y}}$ and $B_{\mathrm{Z}}$ components were equal around $-4 \mathrm{nT}$ up to about 04:10 UT. Then $B_{\mathrm{y}}$ started to become smaller than $B_{\mathrm{Z}}$, reaching a minimum around $-6 \mathrm{nT}$ at 04:12 UT before gradually increasing up to about $-5 \mathrm{nT}$ at 04:17 UT. The time interval when $B_{\mathrm{y}}$ was smaller than $B_{\mathrm{z}}$ occurs at approximately the same time as $\mathrm{C} 1$ and $\mathrm{C} 2$ observed 

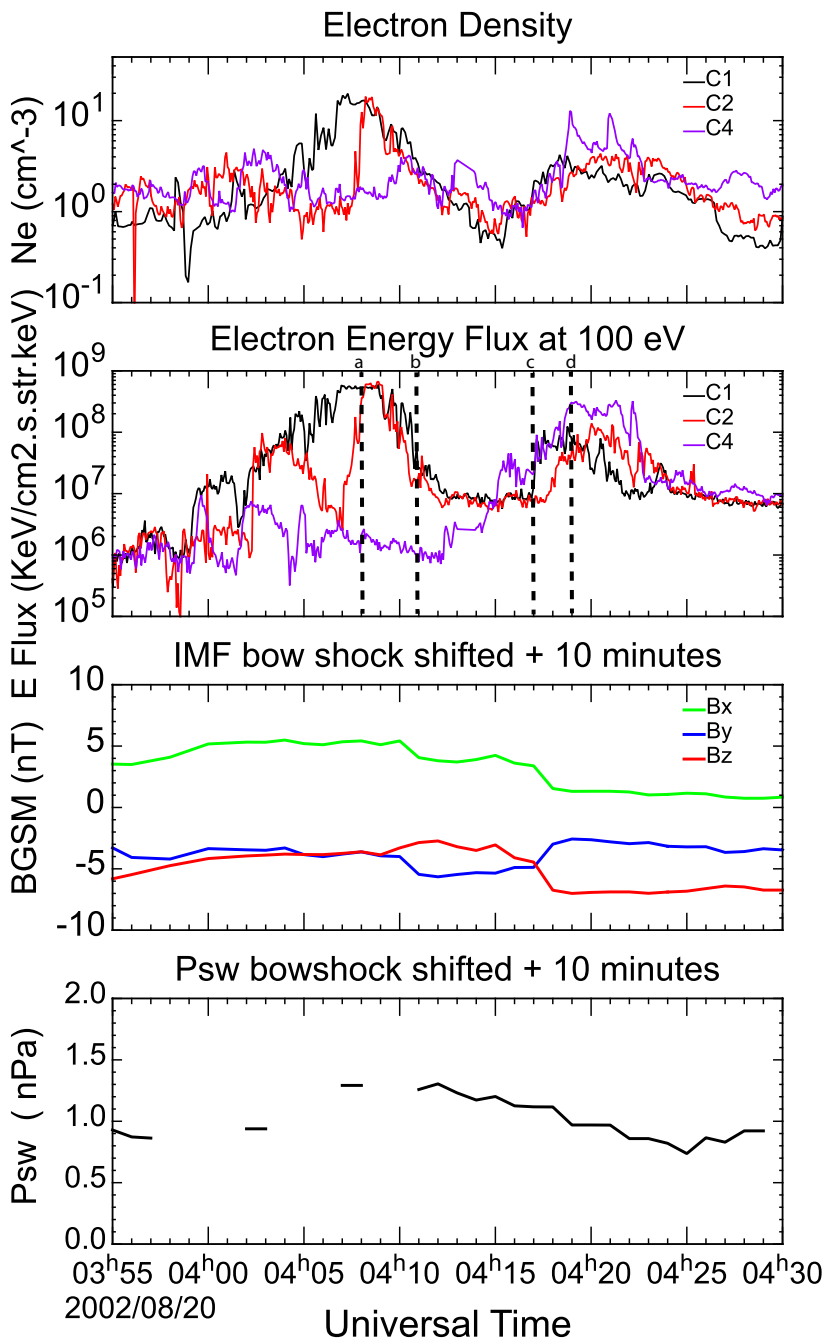

Fig. 5. Top: electron density measured by PEACE on $\mathrm{C} 1$ (black), $\mathrm{C} 2$ (red) and C4 (magenta). Second from top: electron energy flux for an energy around $100 \mathrm{eV}$ from $\mathrm{C} 1, \mathrm{C} 2$ and $\mathrm{C} 4$. Third from top: IMF in GSM. Bottom: solar wind dynamic pressure propagated to the bow shock with $10 \mathrm{~min}$ additional delay for the propagation from the bow shock to the mid-altitude cusp.

the gap in between the two cusps (Fig. 5, 2nd panel from the top). In fact, almost immediately after the decrease of IMF$B_{\mathrm{y}}, \mathrm{C} 2$ left the cusp and, less than a minute later, C1. This would require a fast reaction of the cusp, which is sometimes observed (Etemadi et al., 1988; Sandholt et al., 2002; Escoubet et al., 2008a, b). Of course, some caution must be used in the timing discussion since the propagation of the IMF measured at L1 to the cusp can have an inaccuracy of a few minutes.

According to Newell et al. (1989) and Wing et al. (2010) the cusp would move dawnward in the Northern Hemisphere as IMF- $B_{\mathrm{y}}$ becomes more negative. We have sketched such motion on Fig. 6. The position of $\mathrm{C} 1, \mathrm{C} 2$ and $\mathrm{C} 4$ is shown in an ILAT-MLT diagram for four times: 04:08 UT (a)

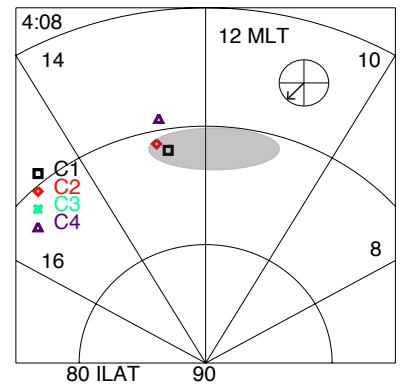

(c)

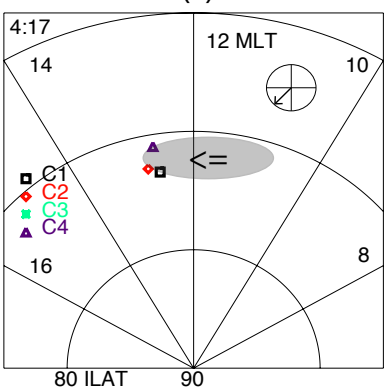

(b)

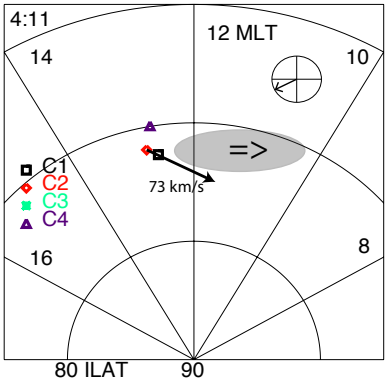

(d)

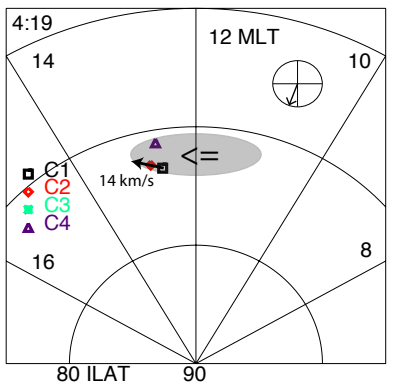

Fig. 6. Sketch of the position of the cusp with respect to $\mathrm{C} 1, \mathrm{C} 2$ and C4 in ILAT-MLT diagrams for four different times: 04:08 UT, 04:11 UT, 04:17 UT and 04:19 UT. These four times are marked on Fig. 5 for reference. The IMF clock angle is indicated in the upper right corner of each diagram. The motion of the boundary of the cusp measured between $\mathrm{C} 1$ and $\mathrm{C} 2$ is given by the thin black arrow. The direction of motion of the cusp is sketched by the wide arrow.

(Fig. 6a), 04:11 UT (Fig. 6b), 04:17 UT (Fig. 6c) and 04:19 UT (Fig. 6d). These times are also marked above the 2nd panel from the top of Fig. 5 (with a, b, c and d) to compare them to the electron fluxes measured by the three spacecraft. In addition, the possible cusp position was shown as a grey oval. We have chosen to represent the cusp as an oval for simplicity since it is similar to statistics for low solar wind pressure obtained by Newell and Meng (1994).

At 04:08 UT (Fig. 6a) both C1 and C2 were in the cusp, while $\mathrm{C} 4$ was equatorward of it on closed field lines. The centre of the cusp was shifted slightly dawnward since $B_{\mathrm{y}}$ was negative with a value of $-3.6 \mathrm{nT}$, approximately equal to $B_{\mathrm{Z}}$. At 04:11 UT (Fig. 6b), due to the decreased IMF- $B_{\mathrm{y}}$ $(-5.5 \mathrm{nT})$ and increased IMF- $B_{\mathrm{Z}}(-2.9 \mathrm{nT})$, the cusp moved dawnward and both $\mathrm{C} 1$ and $\mathrm{C} 2$ left the cusp. Using the time difference between the drop of the flux of $100 \mathrm{eV}$ electrons and the positions of the spacecraft, we estimate the speed of this motion to be around $88 \mathrm{~km} \mathrm{~s}^{-1}$ along the $\mathrm{C} 2-\mathrm{C} 1$ line. If we project this speed in the plane perpendicular to the local magnetic field, which may be closer to the real speed of the cusp, we obtain $73 \mathrm{~km} \mathrm{~s}^{-1}$. This speed is, however, measured along the line joining $\mathrm{C} 2$ and $\mathrm{C} 1$ and gives only an approximation to the real speed of the cusp. After about 6 min, the cusp moved back duskward (Fig. 6c) due to the increase of the $B_{\mathrm{y}}$ component and decrease of the $B_{\mathrm{z}}$ component, which 

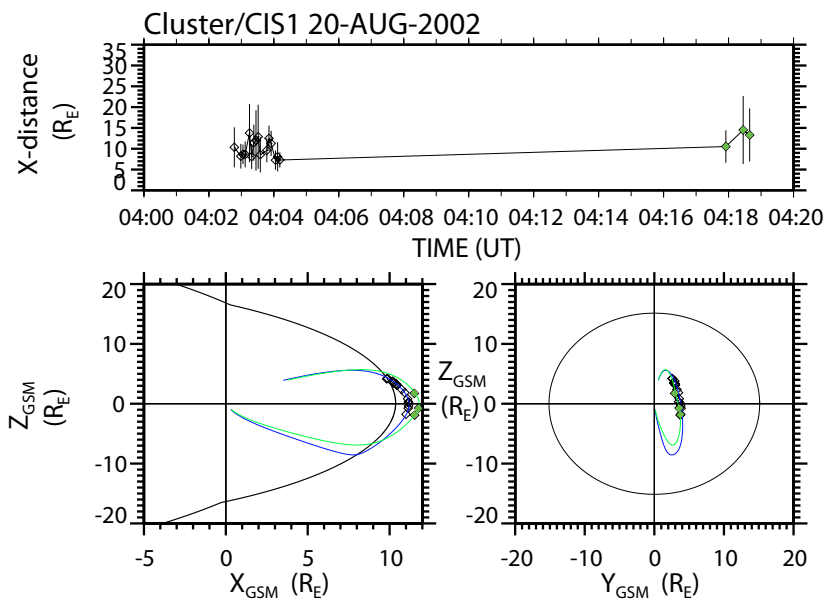

Fig. 7. Top: altitude of injection from the $\mathrm{C} 1$ position deduced from the low energy cut-off of the ion dispersion. The first dispersion is marked with open diamonds and the second one with green diamonds. Bottom left: position of the injection in $X-Z_{\mathrm{GSM}}$ along the Tsyganenko 1996 field lines. In blue for the first dispersion and in green for the second. The magnetopause (Petrinec and Russell, 1996) is shown as a black line. Bottom right: same as left in $Y-Z_{\mathrm{GSM}}$. The T96 model uses the Sibeck et al. (1991) magnetopause model which scales self-similar with pressure, while the Petrinec and Russell (1996) model also considers IMF $B_{\mathrm{Z}}$. Under certain circumstances, the differences in the models can result in a Tsyganenko magnetic field line to be located outside the model magnetopause location.

are then both around $-5 \mathrm{nT}$ at 04:17 UT. The cusp is detected first by $\mathrm{C} 4$ at 04:15:05 UT, followed by $\mathrm{C} 1$ at 04:17:05 UT (Fig. 5, 2nd panel from the top); C2, being duskward of C1, has not yet entered the cusp. Finally, at 04:18:29 UT, $\mathrm{C} 2$ entered the cusp as well. The speed of the cusp is now $23 \mathrm{~km} \mathrm{~s}^{-1}$ along the $\mathrm{C} 1-\mathrm{C} 2$ line and $14 \mathrm{~km} \mathrm{~s}^{-1}$ when projected in the plane perpendicular to the local magnetic field. The analysis of the exit and entry of the cusp by $\mathrm{C} 1$ and $\mathrm{C} 2$ is therefore consistent with a single cusp moving first dawnward and back duskward after a change in the IMF- $B_{\mathrm{y}}$ and $B_{\mathrm{Z}}$ components. This also explains the nested crossing of the gap by $\mathrm{C} 1$ and $\mathrm{C} 2$, with $\mathrm{C} 2$ entering the gap first and leaving the gap last.

We can estimate from the low energy cut-off of the ion dispersion the distance of injection of the ions, and using the Tsyganenko 1996 model (Tsyganenko, 1995), the location where ions have entered the magnetosphere (see Trattner et al., 2004, 2007, for the method). Figures 7 and 8 show the distance and source of injection deduced from the ion dispersion observed on $\mathrm{C} 1$ and $\mathrm{C} 4$, respectively. In the case of $\mathrm{C} 1$, since two dispersions are observed, the two sources are distinguished: open diamonds for the first dispersion and green diamonds for the second. Although we only have three points for the second dispersion, they show the same distance of injection, around $10-15 R_{\mathrm{E}}$, as the first dispersion. Furthermore, the location of the injection at the magnetopause is the
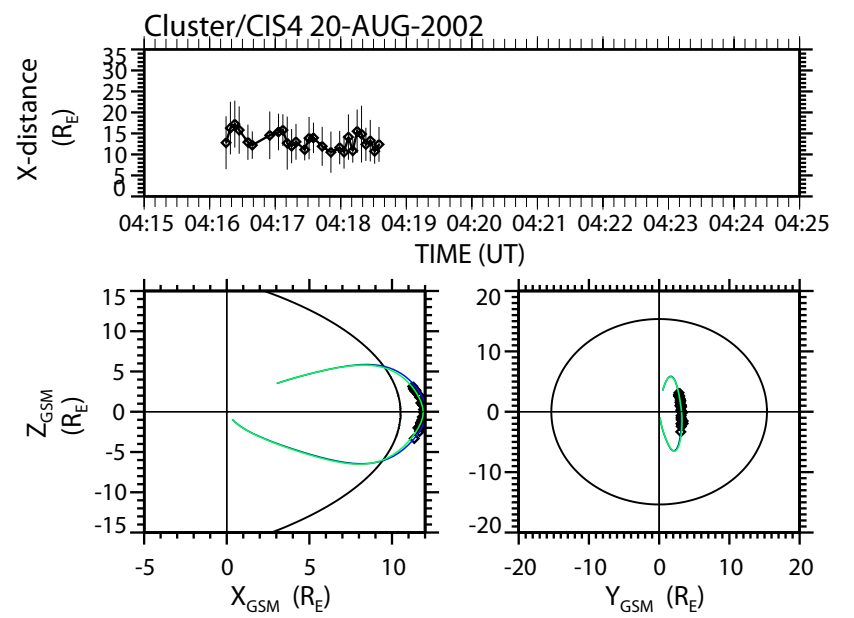

Fig. 8. Same as Fig. 7, but for C4.

same for the first and second dispersion: around the sub-solar point on the post-noon side (Fig. 7 bottom panels). The single dispersion observed by $\mathrm{C} 4$ shows also a distance around $10-15 R_{\mathrm{E}}$ and a source around the equatorial plane on the post-noon side (Fig. 8). This suggests that the source of ions observed by $\mathrm{C} 1$ and $\mathrm{C} 4$ in the polar cusp was located around the same place at the magnetopause. It is an additional argument in favour of the cusp moving back and forth. We also looked at the distance of injection of the ion dispersion detected by $\mathrm{C} 3$ (not shown) and found it very similar to $\mathrm{C} 1$ and C4.

Newell et al. (1989) examined the effect of IMF- $B_{\mathrm{y}}$ on the position of the cusp in magnetic local time. They found that for $\left|B_{\mathrm{y}}\right|>3 \mathrm{nT}$ under $B_{\mathrm{z}}<0$, the peak probability to see the cusp is shifted dawnward by $0.5 \mathrm{~h}$ MLT. Given that they found that the cusp width was about $2.8 \mathrm{~h}$ MLT, this would mean that the dusk border of the cusp would move from $13.4 \mathrm{~h}$ MLT to $12.9 \mathrm{~h}$ MLT. In our case, $\mathrm{C} 1$ and $\mathrm{C} 2$ were at $12.6 \mathrm{~h}$ and $12.8 \mathrm{~h} \mathrm{MLT}$, respectively, when they left the cusp, but according to the statistics they should have stayed in the cusp, although close to its border. One reason to explain this difference is that Newell considered $\left|B_{\mathrm{y}}\right|>3 \mathrm{nT}$, while in our case $B_{\mathrm{y}}$ reaches $-6 \mathrm{nT}$, which could explain why the cusp moved further toward dawn. Crooker et al. (1987), based on magnetic field data, found a displacement of the cusp of $0.75 R_{\mathrm{E}}$ at the magnetopause (their Fig. 5), equivalent to $0.25 \mathrm{~h}$ MLT when $\left|B_{\mathrm{y}}\right|>\left|B_{\mathrm{z}}\right|$. They showed, however, that the cusp maximum displacement predicted by their model could reach up to $7 R_{\mathrm{E}}$ or $3 \mathrm{~h}$ in an extreme case. In our case, it seems that the cusp, assuming a width of $2.8 \mathrm{~h}$ MLT, could have moved by at least $0.9 \mathrm{~h}$ MLT dawnward when $\left|B_{\mathrm{y}}\right|$ becomes twice as large as $\left|B_{\mathrm{z}}\right|$.

We must point out that the IMF observed during the first cusp population is different from the IMF observed during the second population. During the first cusp, $B_{\mathrm{y}}$ is equal to $B_{\mathrm{z}}$ with a value around $-4 \mathrm{nT}$, and during the second 
encounter $B_{\mathrm{y}}$ is around $-3 \mathrm{nT}$ and $B_{\mathrm{z}}$ around $-7 \mathrm{nT}$. Therefore, it is not exactly under the same conditions that we encounter the second cusp. The model from Crooker (1979) would predict reconnection at the low-latitude magnetopause under southward IMF and at the high-latitude pre-noon magnetopause under dawnward IMF. For $B_{\mathrm{y}} \sim B_{\mathrm{z}}$, their model would predict reconnection at intermediate latitude and on the dawnside of the magnetopause. Given that the Cluster observations are slightly on the dusk side (between 12:30 and 13:00 MLT) and that the particle tracing places the equatorward entry points at low latitude magnetopause, we may not have encountered the field lines undergoing anti-parallel reconnection but most likely the ones reconnected by component reconnection (Moore et al., 2002). Since we do not have observations on the dawnside, we cannot exclude that between 04:00 UT and 04:11 UT a double cusp was not formed, as shown by Wing et al. (2001) and Escoubet et al. (2008b); however, the first cusp may be consistent with the lower latitude cusp of Wing et al. (2001) double cusp. What we however can state is that the first cusp observed by $\mathrm{C} 1$ and $\mathrm{C} 2$ was shorter than usual (for comparison $\mathrm{C} 4$ and $\mathrm{C} 3$ observed a longer cusp) due to the quick motion of the cusp toward dawn, and the second cusp was due to the return of the cusp toward dusk.

Measurements of the speed of the cusp have been done in a few cases using Cluster spacecraft near the exterior cusp. Lavraud et al. (2002) found a speed of around $10 \mathrm{~km} \mathrm{~s}^{-1}$ of the boundary between the exterior cusp and the dayside magnetosphere; Vontrat-Reberac (2003) measured both the poleward and equatorward boundaries of the cusp in the range $1-21 \mathrm{~km} \mathrm{~s}^{-1}$ with an average of around $11 \mathrm{~km} \mathrm{~s}^{-1}$; Cargill et al. (2004) estimated a speed of the boundary between the magnetosheath and the exterior cusp of around $30 \mathrm{~km} \mathrm{~s}^{-1}$ and between the exterior cusp and the mantle of around $33 \mathrm{~km} \mathrm{~s}^{-1}$. The speed estimates in this study of the midaltitude cusp are higher when the cusp moved dawnward $\left(70-90 \mathrm{~km} \mathrm{~s}^{-1}\right)$ and around the same values as near the exterior cusp (10-25 $\mathrm{km} \mathrm{s}^{-1}$ ) when it moved back duskward. A possible explanation of this difference in speed is the sharp rotation of the IMF between 04:10 and 04:11 UT and the slow return to its original value that continues up to 04:17 UT. We should, however, be careful with our speed estimations since only two spacecraft observed the cusp boundary and they can only measure the component of the speed along the line that joins them.

We investigated if changes in solar wind dynamic pressure could explain the two cusp populations. Figure 5 (bottom panel) shows the solar wind dynamic pressure between 03:55 UT and 04:30 UT. Although we have a gap in solar wind data around 04:10 UT, the pressure was around $1.3 \mathrm{nPa}$ at 04:08 UT, and about the same value at 04:11 UT. If the pressure stayed constant during the three minutes, which would be a fair assumption given the slow changes of pressures seen during the cusp time interval, it cannot explain why $\mathrm{C} 1$ and $\mathrm{C} 2$ are leaving the cusp at 04:11 UT. If the pres- sure had increased or decreased during these $3 \mathrm{~min}$, we would have expected the position of the cusp to go back to its position by 04:11 UT, but our observations show that the spacecraft left the cusp at that time. During the second encounter of the cusp by $\mathrm{C} 1$ and $\mathrm{C} 2$ around 04:17 UT and 04:18 UT, respectively, the pressure had decreased slightly to $1.1 \mathrm{nPa}$. According to Newell and Meng (1994) (see their Figs. 1 and 2), a decrease of solar wind dynamic pressure would cause the cusp to narrow and move poleward. Using the formula on the effect of the solar wind pressure on the position of the cusp derived by Pitout et al. (2006a, b), a change of pressure from $1.3 \mathrm{nPa}$ down to $1.1 \mathrm{nPa}$ would move the equatorward boundary of the cusp poleward by $0.1^{\circ}$ ILAT and the cusp poleward boundary poleward by $0.08^{\circ}$ ILAT. This is a small motion compared to the separation between $\mathrm{C} 1$ and $\mathrm{C} 2$ in latitude, which was about $0.4^{\circ}$ ILAT at 04:17 UT. Therefore, such a moderate change in solar wind dynamic pressure could not explain the motion of the cusp that we observe with $\mathrm{C} 1$ and $\mathrm{C} 2$.

Crooker et al. (1991) and Newell et al. (2007b) showed that the cusp widens in local time as the merging rate increases. The change of clock angle from $B_{\mathrm{y}}$ dominant to $B_{\mathrm{z}}$ dominant will increase the merging rate, so the motion of the cusp discussed before may also be associated with its widening. We calculated the Newell et al. (2007a) function $\mathrm{d} \Phi_{\mathrm{MP}} / \mathrm{d} t$, which gives the best solar wind magnetosphere coupling function, and found a value of 9767 at 04:15 UT ( $B_{\mathrm{y}}$ dominant) and 13870 at 04:18 UT ( $B_{\mathrm{z}}$ dominant). According to Newell et al. (2007b), these two values falls in the high merging rate domain. If we extrapolate between the mid- and high merging rates (we only have the lower limit of the high merging rate cusps in Newell et al. (2007b), so we will certainly overestimate this widening), we obtain a widening toward dusk (the same toward dawn) of a maximum of 0.29 h MLT between 04:15 and 04:18 UT. Given that $\mathrm{C} 1$ and $\mathrm{C} 2$ separation distance in local time at 04:17 UT was $0.21 \mathrm{~h} \mathrm{MLT}$, the widening of the cusp with the increase of the merging rate could have played a role in the return of the cusp encountered by $\mathrm{C} 1$ and $\mathrm{C} 2$. This effect would, however, be smaller than the motion of the cusp itself estimated around $0.9 \mathrm{~h}$ MLT (see above). We can also compute the widening effect when $\mathrm{C} 1$ and $\mathrm{C} 2$ left the cusp around 04:10 UT, and we found that the cusp would have shrunk by about $0.15 \mathrm{~h}$ MLT. At that time, the separation between C1 and $\mathrm{C} 2$ in local time was $0.19 \mathrm{~h}$ MLT; therefore, the widening of the cusp only would not explain why both $\mathrm{C} 1$ and $\mathrm{C} 2$ left the cusp.

\section{Summary and conclusions}

We have presented a case study of cusp crossings with a time delay between the four Cluster spacecraft varying from a few minutes to a few tens of minutes. $\mathrm{C} 1$ crossed the cusp first and observed two cusp populations separated by a gap 
of precipitation lasting about $6 \mathrm{~min}$. Three minutes later, $\mathrm{C} 2$ also observed two cusp populations at slightly different times than $\mathrm{C} 1$. The third spacecraft, $\mathrm{C} 4$, observed a single cusp population 15 min later and finally $\mathrm{C} 3,42$ min later, also observed a single cusp population.

Due to the nested crossing of $\mathrm{C} 1$ and $\mathrm{C} 2$ through the gap between the two cusp populations, $\mathrm{C} 2$ being first to leave the cusp and last to re-enter it, these observations are difficult to be explained by two distinct cusps with a gap in between. However, since we observe the cusp in a narrow area of local time post-noon, a second higher latitude cusp, which would be expected from the anti-parallel reconnection, may have been present in the pre-noon sector but could not be observed.

On the other hand, these observations are in agreement with a motion of the cusp first dawnward and then back duskward since:

- $\mathrm{C} 1$ and $\mathrm{C} 2$ recorded a motion of the cusp toward dawn with a speed around $70-90 \mathrm{~km} \mathrm{~s}^{-1}$ and a return toward dusk with a speed around $10-25 \mathrm{~km} \mathrm{~s}^{-1}$;

- during the cusp motion, the IMF changed for about 6 min, with $B_{\mathrm{y}}$ becoming more negative and larger in absolute value than $B_{\mathrm{z}}$;

- the source of injection of ions estimated using the energy cut-off of the ion dispersions observed by $\mathrm{C} 1$ and $\mathrm{C} 4$ always lies around the equatorial plane at the magnetopause, slightly on the duskside.

The moderate change in solar wind dynamic pressure around $0.2 \mathrm{nPA}$ would not explain the motion of the cusp observed since it would induce a motion of the cusp that is smaller than the separation distance between $\mathrm{C} 1$ and $\mathrm{C} 2$. The widening of the cusp with the increase of the merging rate may have played a role in the encounter of the second cusp, but not when $\mathrm{C} 1$ and $\mathrm{C} 2$ left the first cusp.

All these observations clearly favour a motion of the cusp induced by the change of IMF orientation. The cusp would have moved toward the dawn flank as IMF- $B_{\mathrm{y}}$ was becoming dominant and back toward the sub-solar point when the IMF$B_{\mathrm{Z}}$ was southward dominant.

Acknowledgements. The Cluster Active Archive and the instrument teams are acknowledged for the access to Cluster data. We thank the Space Physics Data Facility (SPDF) and the National Space Science Data Center (NSSDC); N. F. Ness, Bartol Research Institute, USA; and McComas, SWRI, USA for the provision of solar wind data. Data analysis was done with the QSAS science analysis system provided by the United Kingdom Cluster Science Centre (Imperial College London and Queen Mary, University of London). Research at UCLA was supported by NASA grants NNX12AD18G. The work at Lockheed Martin was supported by NASA contracts NNX08AF35G and NNX11AJ09G. B.G. acknowledges support of grant GACR P209/11/P848. The work at IRAP is supported by the French Space Agency, CNES.
Topical Editor L. Blomberg thanks P. E. Sandholt and one anonymous referee for their help in evaluating this paper.

\section{References}

Berchem, J., Marchaudon, A., Dunlop, M., Escoubet, C. P., Bosqued, J. M., Reme, H., Dandouras, I., Balogh, A., Lucek, E., Carr, C., and Pu, Z.: Reconnection at the dayside magnetopause: Comparisons of global MHD simulation results with Cluster and Double Star observations, J. Geophys. Res., 113, A07S12, doi:10.1029/2007JA012743, 2008.

Burch, J. L.: Precipitation of low-energy electrons at high latitudes: Effects of interplanetary magnetic field and dipole tilt angle, J. Geophys. Res., 77, 6696-6707, doi:10.1029/JA077i034p06696, 1972.

Burch, J. L., Reiff, P. H., Spiro, R. W., Heelis, R. A., and Fields, S. A.: Cusp region particle precipitation and ion convection for northward interplanetary magnetic field, Geophys. Res. Lett., 7, 393-396, 1980.

Candidi, M., Kroehl, H. W., and Meng, C. I.: Intensity distribution of dayside polar soft electron precipitation and the IMF, Planet. Space Sci., 31, 489-498, 1983.

Carbary, J. F. and Meng, C.-I.: Relations between the interplanetary magnetic field $B_{\mathrm{Z}}, \mathrm{AE}$ index, and cusp latitude, J. Geophys. Res., 91, 1549-1556, 1986.

Cargill, P. J., Dunlop, M. W., Lavraud, B., Elphic, R. C., Holland, D. L., Nykyri, K., Balogh, A., Dandouras, I., and Rème, H.: CLUSTER encounters with the high altitude cusp: boundary structure and magnetic field depletions, Ann. Geophys., 22, 1739-1754, doi:10.5194/angeo-22-1739-2004, 2004.

Crooker, N. U.: Dayside merging and cusp geometry, J. Geophys. Res., 84, 951-959, doi:10.1029/JA084iA03p00951, 1979.

Crooker, N. U., Berchem, J., and Russell, C. T.: Cusp displacement at the magnetopause for large IMF Y component, J. Geophys. Res., 92, 13467-13471, doi:10.1029/JA092iA12p13467, 1987.

Crooker, N. U., Toffoletto, F. R., and Gussenhoven, M. S.: Opening the cusp, J. Geophys. Res., 96, 3497-3503, 1991.

Dunlop, M. W., Zhang, Q.-H., Xiao, C.-J., He, J.-S., Pu, Z., Fear, R. C., Shen, C., Escoubet, C. P.: Reconnection at high latitudes: Anti-parallel merging, Phys. Rev. Lett., 102, 075005, doi:10.1103/PhysRevLett.102.075005, 2009.

Escoubet, C. P. and Bosqued, J. M.: The influence of IMF-Bz and/or AE on the polar cusp: An overview of observations from the AUREOL-3 satellite, Planet. Space Sci., 37, 609-626, 1989.

Escoubet, C. P., Bosqued, J. M., Hoffman, R. A., Berthelier, A., and Anderson, P. C.: Opposite ion dispersions observed quasisimultaneously in the polar cusp by the AUREOL-3 and DE 2 satellites, Geophys. Res. Lett., 24, 2487-2490, 1997.

Escoubet, C. P., Fehringer, M., and Goldstein, M.: Introduction: The Cluster mission, Ann. Geophys., 19, 1197-1200, doi:10.5194/angeo-19-1197-2001, 2001.

Escoubet, C. P., Berchem, J., Bosqued, J. M., Trattner, K. J., Taylor, M. G. G. T., Pitout, F., Laakso, H., Masson, A., Dunlop, M., Dandouras, I., Reme, H., Fazakerley, A. N., and Daly, P.: Effect of a northward turning of the interplanetary magnetic field on cusp precipitation as observed by Cluster, J. Geophys. Res., 113, A07S13, doi:10.1029/2007JA012771, 2008a.

Escoubet, C. P., Berchem, J., Bosqued, J. M., Trattner, K. J., Taylor, M. G. G. T., Pitout, F., Vallat, C., Laakso, H., Masson, A., 
Dunlop, M., Reme, H., Dandouras, I., and Fazakerley, A.: Two sources of magnetosheath ions observed by Cluster in the midaltitude polar cusp, Adv. Space Res., 41, 1528-1536, 2008b.

Etemadi, A., Cowley, S. W. H., Lockwood, M., Bromage, B. J. I., Willis, D. M., and Luehr, H.: The dependence of high-latitude dayside ionospheric flows on the north-south component of the IMF: A high time resolution correlation analysis using the EISCAT POLAR and AMPTE UKS and IRM data, Planet. Space Sci., 36, 471-498, doi:10.1016/0032-0633(88)90107-9, 1988.

Frank, L. A.: Plasma in the Earth's polar magnetosphere, J. Geophys. Res., 76, 5202-5219, 1971.

Heikkila, W. J. and Winningham, J. D.: Penetration of magnetosheath plasma to low altitudes through the dayside magnetospheric cusps, J. Geophys. Res., 76, 883-891, doi:10.1029/JA076i004p00883, 1971.

Johnstone, A. D., Alsop, C., Burge, S., Carter, P. J., Coates, A. J., Coker, A. J., Fazakerley, A. N., Grande, M., Gowen, R. A., Gurgiolo, C., Hancock, B. K., Narheim, B., Preece, A., Sheather, P. H., Winningham, J. D., and Woodliffe, R. D.: PEACE: A plasma electron and current experiment, Space Sci. Rev., 79, 351-398, 1997.

Lavraud, B., Dunlop, M. W., Phan, T. D., Rème, H., Bosqued, J.M., Dandouras, I., Sauvaud, J.-A., Lundin, R., Taylor, M. G. G. T., Cargill, P. J., Mazelle, C., Escoubet, C. P., Carlson, C. W., McFadden, J. P., Parks, G. K., Moebius, E., Kistler, L. M., Bavassano-Cattaneo, M.-B., Korth, A., Klecker, B., and Balogh, A.: Cluster observations of the exterior cusp and its surrounding boundaries under northward IMF, Geophys. Res. Lett., 29, 1995, doi:10.1029/2002GL015464, 2002.

Moore, T. E., Fok, M.-C., and Chandler, M. O.: The dayside reconnection $\mathrm{X}$ line, J. Geophys. Res., 107, 1332, doi:10.1029/2002JA009381, 2002.

Newell, P. and Meng, C.: Ionospheric projections of magnetospheric regions under low and high solar wind pressure conditions, J. Geophys. Res., 99, 273-286, 1994.

Newell, P. T., Meng, C.-I., Sibeck, D. G., and Lepping, R.: Some low-altitude cusp dependencies on the interplanetary magnetic field, J. Geophys. Res., 94, 8921-8927, 1989.

Newell, P. T., Sotirelis, T., Liou, K., Meng, C.-I., and Rich, F. J.: A nearly universal solar wind-magnetosphere coupling function inferred from 10 magnetospheric state variables, J. Geophys. Res., 112, A01206, doi:10.1029/2006JA012015, 2007a.

Newell, P. T., Wing, S., and Rich, F. J.: Cusp for high and low merging rates, J. Geophys. Res., 112, A09205, doi:10.1029/2007JA012353, 2007b.

Newell, P. T., Lee, A. R., Liou, K., Ohtani, S., Wing, S., and Hairston, M.: Multisatellite low-altitude observations of a magnetopause merging burst, J. Geophys. Res., 115, A11204, doi:10.1029/2010JA015438, 2010.

Petrinec, S. M. and Russell, C. T.: Near-Earth magnetotail shape and size as determined from the magnetopause flaring angle, J. Geophys. Res., 101, 137-152, 1996.

Pitout, F., Newell, P. T., and Buchert, S. C.: Simultaneous highand low-latitude reconnection: ESR and DMSP observations, Ann. Geophys., 20, 1311-1320, doi:10.5194/angeo-20-13112002, 2002.

Pitout, F., Escoubet, C. P., Bogdanova, Y. V., Georgescu, E., Fazakerley, A. N., and Rème, H.: Response of the mid-altitude cusp to rapid rotations of the IMF, Geophys. Res. Lett., 33, L11107,
doi:10.1029/2005GL025460, 2006a.

Pitout, F., Escoubet, C. P., Klecker, B., and Rème, H.: Cluster survey of the mid-altitude cusp: 1. size, location, and dynamics, Ann. Geophys., 24, 3011-3026, doi:10.5194/angeo-243011-2006, 2006b.

Pitout, F., Escoubet, C. P., Klecker, B., and Dandouras, I.: Cluster survey of the mid-altitude cusp - Part 2: Large-scale morphology, Ann. Geophys., 27, 1875-1886, doi:10.5194/angeo-271875-2009, 2009.

Reiff, P. H., Burch, J. L., and Hill, T. W.: Solar wind plasma injection at the dayside magnetospheric cusp, J. Geophys. Res., 82, 479-491, 1977.

Reiff, P. H., Spiro, R. W., and Burch, J. L.: Cusp proton signatures and the interplanetary magnetic field, J. Geophys. Res., 85, 5997-6005, 1980.

Rème, H., Aoustin, C., Bosqued, J. M., Dandouras, I., Lavraud, B., Sauvaud, J. A., Barthe, A., Bouyssou, J., Camus, Th., Coeur-Joly, O., Cros, A., Cuvilo, J., Ducay, F., Garbarowitz, Y., Medale, J. L., Penou, E., Perrier, H., Romefort, D., Rouzaud, J., Vallat, C., Alcaydé, D., Jacquey, C., Mazelle, C., d'Uston, C., Möbius, E., Kistler, L. M., Crocker, K., Granoff, M., Mouikis, C., Popecki, M., Vosbury, M., Klecker, B., Hovestadt, D., Kucharek, H., Kuenneth, E., Paschmann, G., Scholer, M., Sckopke, N., Seidenschwang, E., Carlson, C. W., Curtis, D. W., Ingraham, C., Lin, R. P., McFadden, J. P., Parks, G. K., Phan, T., Formisano, V., Amata, E., Bavassano-Cattaneo, M. B., Baldetti, P., Bruno, R., Chionchio, G., Di Lellis, A., Marcucci, M. F., Pallocchia, G., Korth, A., Daly, P. W., Graeve, B., Rosenbauer, H., Vasyliunas, V., McCarthy, M., Wilber, M., Eliasson, L., Lundin, R., Olsen, S., Shelley, E. G., Fuselier, S., Ghielmetti, A. G., Lennartsson, W., Escoubet, C. P., Balsiger, H., Friedel, R., Cao, J.-B., Kovrazhkin, R. A., Papamastorakis, I., Pellat, R., Scudder, J., and Sonnerup, B.: First multispacecraft ion measurements in and near the Earth's magnetosphere with the identical Cluster ion spectrometry (CIS) experiment, Ann. Geophys., 19, 1303-1354, doi:10.5194/angeo19-1303-2001, 2001.

Rosenbauer H., Grunwaldt, H., Montgomery, M. D., Paschmann, G., and Sckopke, N.: Heos 2 plasma observations in the distant polar magnetosphere: the plasma mantle, J. Geophys. Res., 80, 2723-2737, 1975.

Sandholt, P. E., Farrugia, C. J., Burlaga, L. F., Holtet, J. A., Moen, J., Lybekk, B., Jacobsen, B., Opsvik, D., Egeland, A., Lepping, R., Lazarus, A. J., Hansen, T., Breckke, A., and Friis-Christensen, E.: Cusp/cleft auroral activity in relation to solar wind dynamic pressure, interplanetary magnetic field $B_{\mathrm{Z}}$ and $B_{\mathrm{y}}$, J. Geophys. Res., 99, 17323-17342, 1994.

Sandholt, P. E., Farrugia, C. J., Moen, J., and Cowley, S. W. H.: Dayside auroral configurations: Responses to southward and northward rotations of the interplanetary magnetic field, J. Geophys. Res., 103, 20279-20295, doi:10.1029/98JA01541, 1998.

Sandholt, P. E., Farrugia, C. J., Moen, J., and Denig, W. F.: The cusp in rapid transition, J. Geophys. Res., 107, 1427, doi:10.1029/2001JA009214, 2002.

Shelley, E. G., Sharp, R. D., and Johnson, R. G.: He++ and $\mathrm{H}+$ flux measurements in the day side cusp: Estimates of convection electric field, J. Geophys. Res., 81, 2363-2370, doi:10.1029/JA081i013p02363, 1976.

Sibeck, D. G., Lopez, R. E., and Roelof, E. C.: Solar wind control of the magnetopause shape, location, and motion, J. Geophys. Res., 
96, 5489-5495, 1991.

Trattner, K. J., Fuselier, S. A., and Petrinec, S. M.: Location of the reconnection line for northward interplanetary magnetic field, J. Geophys. Res., 109, A03219, doi:10.1029/2003JA009975, 2004.

Trattner, K. J., Fuselier, S. A., Petrinec, S. M., Yeoman, T. K., Mouikis, C., Kucharek, H., and Reme, H.: Reconnection sites of spatial cusp structures, J. Geophys. Res., 110, A04207, doi:10.1029/2004JA010722, 2005.

Trattner, K. J., Mulcock, J. S., Petrinec, S. M., and Fuselier, S. A.: Probing the boundary between anti-parallel and component reconnection during southwards interplanetary magnetic field conditions, J. Geophys. Res., 112, A08210, doi:10.1029/2007JA012270, 2007.

Tsyganenko, N. A.: Modeling the Earth's magnetospheric magnetic field confined within a realistic magnetopause, J. Geophys. Res., 100, 5599-5612, 1995.

Tsyganenko, N. A. and Stern, D. P.: Modeling the global magnetic field of the large-scale Birkeland current systems, J. Geophys. Res., 101, 27187-27198, 1996.

Vontrat-Reberac, A.: Etude des cornets polaires: observations insitu et signatures ionospheriques, $\mathrm{PhD}$ Thesis, Université de Versailles-Saint-Quentin, 2003.
Wilken, B., Daly, P. W., Mall, U., Aarsnes, K., Baker, D. N., Belian, R. D., Blake, J. B., Borg, H., Büchner, J., Carter, M., Fennell, J. F., Friedel, R., Fritz, T. A., Gliem, F., Grande, M., Kecskemety, K., Kettmann, G., Korth, A., Livi, S., McKenna-Lawlor, S., Mursula, K., Nikutowski, B., Perry, C. H., Pu, Z. Y., Roeder, J., Reeves, G. D., Sarris, E. T., Sandahl, I., Søraas, F., Woch, J., and Zong, Q.-G.: First results from the RAPID imaging energetic particle spectrometer on board Cluster, Ann. Geophys., 19, 1355-1366, doi:10.5194/angeo-19-1355-2001, 2001.

Wing, S., Newell, P. T., and Ruohoniemi, J. M.: Double cusp: Model prediction and observational verification, J. Geophys. Res., 106, 25571-25593, doi:10.1029/2000JA000402, 2001.

Wing, S., Ohtani, S., Newell, P. T., Higuchi, T., Ueno, G., and Weygand, J. M.: Dayside field-aligned current source regions, J. Geophys. Res., 115, A12215, doi:10.1029/2010JA015837, 2010.

Woch, J. and Lundin, R.: Magnetosheath plasma precipitation in the polar cusp and its control by the interplanetary magnetic field, J. Geophys. Res., 97, 1421-1430, 1992.

Zhou, X. W., Russell, C. T., Le, G., Fuselier, S. A., and Scudder, I. D.: Solar wind control of the polar cusp at high altitude, J. Geophys. Res., 105, 245-251, 2000. 